\title{
Integrating Pricing And Distribution Decisions In Multiple Markets
}

Kingsley Gnanendran, (Email: skg355@Scranton.edu), University of Scranton

Ying Chien, University of Scranton

\begin{abstract}
This paper deals with the simultaneous optimization of prices and shipment quantities in a supply network when the supplier has the market power to set prices, thereby influencing demand directly. We focus on the distribution stage of the supply chain where the firm's products are shipped from several locations (plants, warehouses) to various independent markets, and address the following questions: (i) what is the best price at each market?, and (ii) what is the best distribution plan given these prices? The combined problem can be modeled as a nonlinear optimization problem. For its solution, we propose an iterative linear programming approach that utilizes shadow price information from a series of successive transportation problems. To evaluate the heuristic's effectiveness, we compare it with a "brute-force" enumeration using a grid-search. The grid-search is implemented on a spreadsheet with a programming loop to facilitate repeated invocation of the transportation problem solver routine.
\end{abstract}

\section{INTRODUCTION}

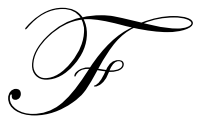

acing ever-increasing competition in today's markets, companies now realize that improvements of internal operations and cost reduction measures alone are not adequate to stay competitive. Beyond the implementation of manufacturing management philosophies and technologies such as just-in-time manufacturing, total quality management, and enterprise resource planning, companies in recent years have broadened their attention to all linked business processes and activities required to meet customers' requirements. As a result, supply chain management has become a major focus of today's business management in order to further reduce costs, increase market share, and improve profits.

A successful supply chain requires strong linkages of all stages of the chain, both between organizations and within a particular organization. This paper is concerned with the distribution stage of the supply chain where a firm's products are shipped from several supply locations (plants, warehouses) to be sold in various independent markets. The standard transportation linear programming model is usually adequate to solve the problem of minimizing the cost of satisfying total demand at all markets subject to supply limitations at the sources [Chopra and Meindl (2004)]. In conventional formulations of this problem, the supply and demand quantities are assumed to be fixed and known in advance. Such an assumption may be valid for commodity products, but when the firm has market power and is able to influence demand through price setting, the static demand assumption is unrealistic. The marketing literature abounds with models for matching pricing strategies to markets [e.g. Duke (1994)] but our focus here is on the effect of the price on demand and, consequently, its effect on an operational decision. In a previous study, Dökmeci (1998) considered the effect of a uniform price (across several markets) on the facility location decision. Here, we examine the effect of price on demand allocation given that the locations of the supply facilities have already been well established. Also, in contrast to the Dökmeci paper, we assume that different prices may be set at different markets.

The key issues in the demand allocation problem when prices can vary are: (i) what is the best set of prices for a given set of markets? (the pricing subproblem), and (ii) what is the best shipping plan at these prices? (the distribution subproblem). In this paper, we provide a mathematical programming formulation for the problem of simultaneously optimizing prices and shipment quantities when demand is a function of the price set by the decision maker. Since the incorporation of variable pricing causes the loss of linearity in the model, one cannot use standard linear programming (LP) techniques to solve it. We propose, instead, a heuristic methodology that is based on solving a series of fixed-demand 
transportation subproblems to iteratively adjust prices and demands in the broader model. Starting at an arbitrary but feasible price vector, the heuristic uses shadow price information gleaned from the optimal solution to the corresponding transportation problem to modify the market demands. The transportation problem is then re-solved with these new demand quantities in order to generate a fresh set of shadow prices, and the cycle repeated until there is no further improvement in the objective function value. To evaluate the efficacy of our approach, we compare it with a "brute-force" grid search strategy. The grid search is implemented on Microsoft Excel enhanced with programming extensions provided by VBA (Visual Basic for Applications). VBA enables the use of a programming loop to repeatedly invoke the LP solver, and to keep track of the best solution.

The rest of this paper is organized in the following sequence: formulation of the model, development of the heuristic methodology, numerical example, grid search, and concluding comments.

\section{FORMULATION} objective:

We begin with the following notation for a standard transportation problem with a profit maximization

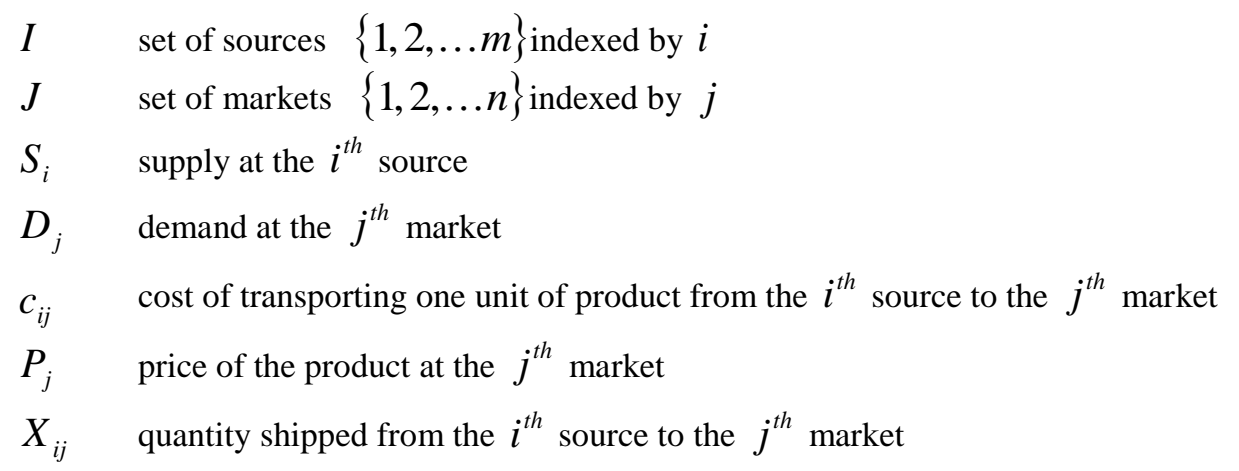
written as:

When prices, and hence demands, are fixed the standard linear programming transportation model can be

(P1)

$$
\text { Maximize } Z_{1}=\sum_{j \in J} P_{j} D_{j}-\sum_{i \in I} \sum_{j \in J} c_{i j} X_{i j}
$$

subject to:

$$
\begin{aligned}
\sum_{j \in J} X_{i j} \leq S_{i} & \forall i \\
\sum_{i \in I} X_{i j}=D_{j} & \forall j \\
X_{i j} \geq 0 & \forall i, j
\end{aligned}
$$

Now suppose that $D_{j}$ is a function of the price charged at the $j^{\text {th }}$ market, i.e. $D_{j}=f_{j}\left(P_{j}\right)$, with a linear functional form:

$$
D_{j}=a_{j}-b_{j} P_{j} \quad \forall j
$$




$$
P_{j}^{L} \leq P_{j} \leq P_{j}^{U} \quad \forall j
$$

where $a_{j}, b_{j}>0$ for all $j$. The model can then be recast as:

$$
\text { Maximize } \quad Z_{2}=\sum_{j \in J} P_{j}\left(a_{j}-b_{j} P_{j}\right)-\sum_{i \in I} \sum_{j \in J} c_{i j} X_{i j}
$$

subject to:

(P2)

$$
\sum_{j \in J} X_{i j} \leq S_{i} \quad \forall i
$$

$$
P_{j}^{L} \leq P_{j} \leq P_{j}^{U} \quad \forall \quad j
$$

Note that while model (P1) is a linear program, model (P2) is a linearly constrained program with: (i) a quadratic objective function due to the $P_{j}{ }^{2}$ term in eq. (7), and (ii) simple bounds on the variables (eq. (11)). Note also that the standard transportation model structure of the constraints is lost due to the additional $P_{j}$ variables in eq. (9).

\section{HEURISTIC METHOD}

This section gives the technical details of the proposed heuristic for solving model (P2). The method attempts to find the best market demands (and corresponding market prices) in model (P2) by using shadow price information from model (P1).

\section{Method}

According to linear programming theory, the shadow price of a constraint is defined as the change in objective value per unit change in the RHS-value of that constraint. Let the shadow price of the $j^{\text {th }}$ market demand constraint in the standard transportation model, i.e., eq. (3) in model (P1), be $S P_{j}$, with a reported range of validity of $\left[D_{j}^{\min }, D_{j}^{\max }\right]$. Suppose now that demand at this market is increased (within the above range of validity) by $\delta_{j}$, the change in objective function value can be computed as:

$$
\Delta Z_{1}=S P_{j} * \delta_{j}
$$

Note that this expression includes the amount $P_{j} \delta_{j}$ representing the increase in revenue due to the increased demand, and is computed on the basis of a fixed market price of $P_{j}$. However, since price must decrease in order to induce this increase in demand (eq. (5)), the amount $P_{j} \delta_{j}$ is an overestimate of the true increase in revenue and an 
adjustment should be made to the computation of $\Delta Z_{1}$ in eq (12) to account for this. Let $P_{j}^{\prime}$ be the price when demand is $D_{j}+\delta_{j}$. From eq. (5):

$D_{j}+\delta_{j}=a_{j}-b_{j} P_{j}^{\prime}$

$b_{j} P_{j}^{\prime}=a_{j}-D_{j}-\delta_{j}$

$P_{j}^{\prime}=P_{j}-\left(\delta_{j} / b_{j}\right)$

Let the true increase in revenue as a result of a price change from $P_{j}$ to $P_{j}^{\prime}$ be $\Delta R . \Delta R$ is given by:

$$
\begin{aligned}
\Delta R & =P_{j}^{\prime}\left(D_{j}+\delta_{j}\right)-P_{j} D_{j} \\
& =\left[P_{j}-\left(\delta_{j} / b_{j}\right)\right]\left(D_{j}+\delta_{j}\right)-P_{j} D_{j} \quad \text { [from eq. (13)] } \\
& =P_{j} \delta_{j}-\left(\delta_{j} / b_{j}\right)\left(D_{j}+\delta_{j}\right)
\end{aligned}
$$

The change in the objective function value, eq. (12), should then read:

$\Delta Z_{1}=S P_{j} * \delta_{j}+$ true increase in revenue - erroneous estimate of increase in revenue

$$
\begin{aligned}
& =S P_{j} * \delta_{j}+\Delta R-P_{j} \delta_{j} \\
& =S P_{j} * \delta_{j}+P_{j} \delta_{j}-\left(\delta_{j} / b_{j}\right)\left(D_{j}+\delta_{j}\right)-P_{j} \delta_{j} \quad \text { [from eq. (14)] } \\
& =S P_{j} * \delta_{j}-\left(\delta_{j} / b_{j}\right)\left(D_{j}+\delta_{j}\right)
\end{aligned}
$$

We define an adjusted shadow price ( $A S P$ ) by letting $\delta_{j}$, the change in the RHS value of the constraint, be equal to 1 . Thus,

$$
A S P_{j}=S P_{j}-\left(1 / b_{j}\right)\left(D_{j}+1\right)
$$

From eqs. (5) and (6), the range of possible demand values at the $j^{\text {th }}$ market is in the range: $\left[a_{j}-b_{j} P_{j}^{U}, a_{j}-b_{j} P_{j}^{L}\right]$. Combining this range with the range of validity of the corresponding shadow price, $\left[D_{j}^{\min }, D_{j}^{\max }\right]$, the effective lower and upper limits of demand in market $j$ for $A S P_{j}$ are as follows (see also Figure 1).

$\left[\max \left\{D_{j}^{\min }, a_{j}-b_{j} P_{j}^{U}\right\}, \min \left\{D_{j}^{\max }, a_{j}-b_{j} P_{j}^{L}\right\}\right]$ 
The proposed heuristic method uses these ASPs to iteratively modify market demands within their effective ranges. The steps are as follows:

- $\quad$ Step 1: In model (P1), set each market's price to the midpoint of its permitted range. Solve the resulting transportation LP.

- $\quad$ Step 2: Use the shadow price information from the LP to compute ASPs [eq. (16)]. Choose the market with the largest absolute value of $A S P$ and adjust it's demand to the effective upper limit of validity if the chosen $A S P$ is positive, or effective lower limit of validity if the ASP is negative [eq. (17)].

- $\quad$ Step 3: Solve the modified transportation problem. If the objective function value has improved, go to Step 2; else, STOP.

Figure 1: Effective Limits Of Validity For Adjusted Shadow Prices

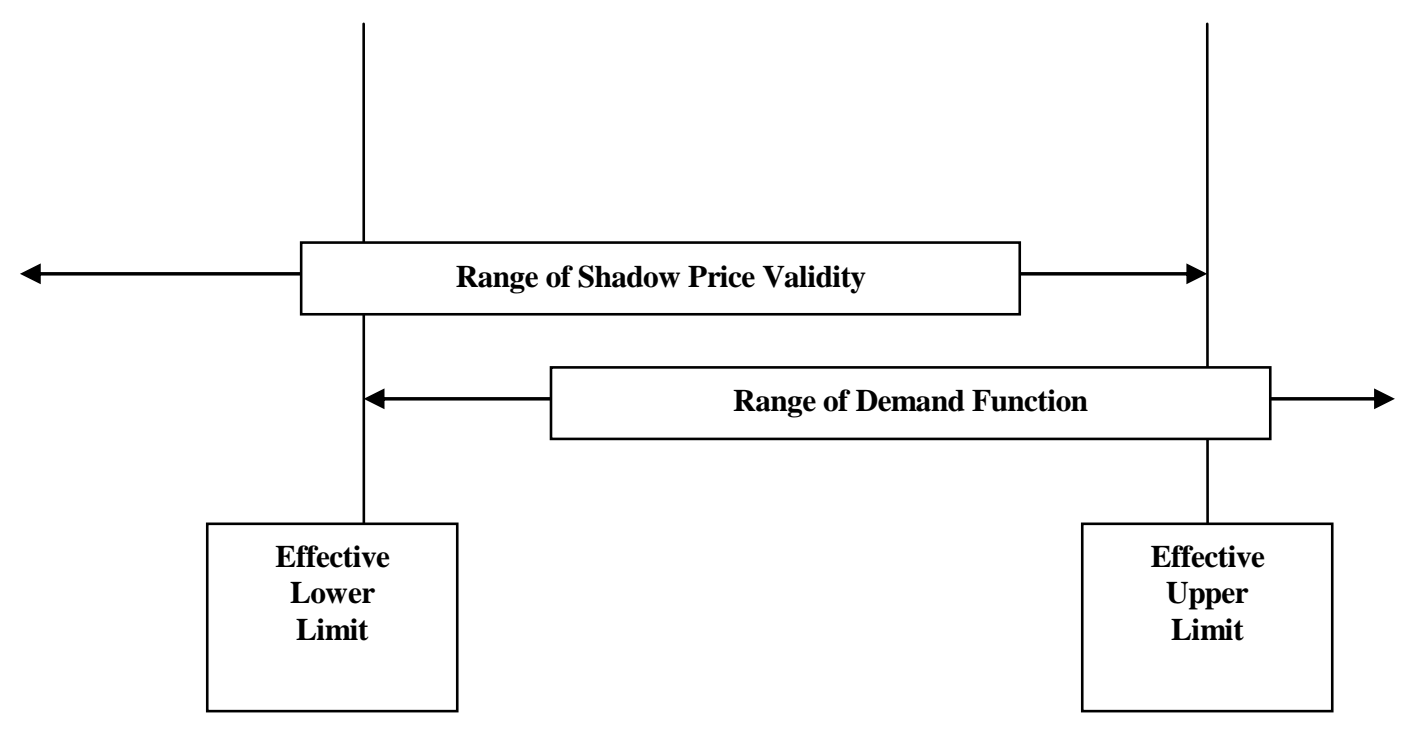

\section{Numerical Example}

Tables 1 and 2 give the data for a sample problem. The price-elastic demand functions for Markets 1 and 2 are depicted in Figure 2 for illustration.

Table 1: Demand Function Data For Sample Problem

\begin{tabular}{|c|c|c|c|c|}
\hline Market & Market 1 & Market 2 & Market 3 & Market 4 \\
\hline \multicolumn{5}{|c|}{ Demand Function } \\
\hline Intercept & 6020 & 4020 & 2020 & 1520 \\
\hline Slope & -400 & -200 & -120 & -50 \\
\hline \multicolumn{7}{|c|}{ Price Range } \\
\hline Minimum & $\$ 10$ & $\$ 8$ & $\$ 9$ & 11 \\
\hline Maximum & 11 & 10 & 13 \\
\hline
\end{tabular}

Table 2: Unit Transportation Costs And Supply Limits For Sample Problem

\begin{tabular}{|c|c|c|c|c|c|}
\hline Source & Market 1 & Market 2 & Market 3 & Market 4 & Supply \\
\hline Source 1 & $\$ 3$ & $\$ 4$ & 7 & 11 & 5000 \\
\hline Source 2 & 4 & 3 & 5 & 8 & 6000 \\
\hline Source 3 & 5 & 2 & 4 & 7 & 2500 \\
\hline
\end{tabular}


Figure 2: Demand Functions At Markets 1 And 2

Market 1

Demand

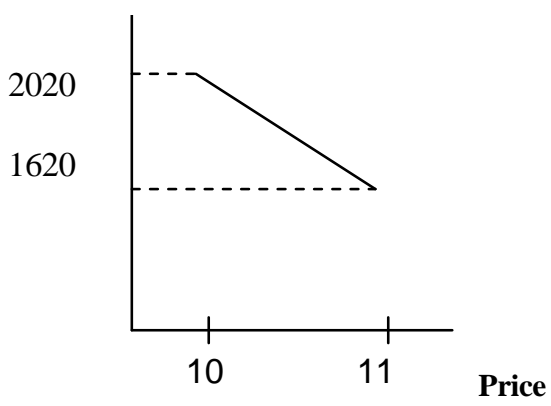

Market 2

Demand

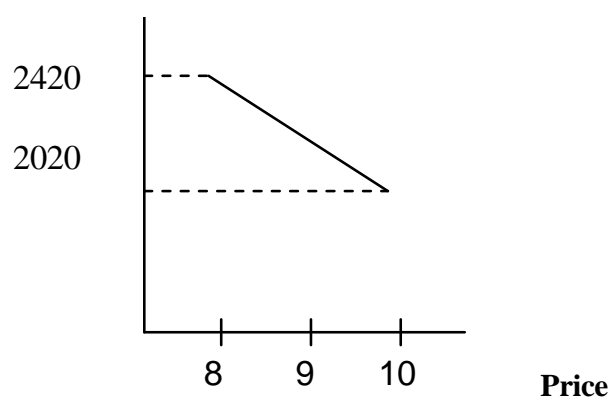

First, the price at each market is set at the midpoint of the corresponding price range (e.g., for Market 1, it is set at $\$ 10.50$ ). The resulting demands at the four markets are 1820, 2220, 820, and 920, respectively. Hence, we solve the following transportation problem:

\begin{tabular}{|c|c|c|c|c|c|}
\hline Source & Market 1 & Market 2 & Market 3 & Market 4 & Supply \\
\hline Source 1 & $\$ 3$ & $\$ 4$ & $\$ 7$ & $\$ 11$ & 5000 \\
\hline Source 2 & 4 & 3 & 5 & 8 & 6000 \\
\hline Source 3 & 5 & 2 & 4 & 9 & 2500 \\
\hline Demand & 1820 & 2220 & 820 & 920 & \\
\hline Price & $\$ 10.50$ & $\$ 9.00$ & $\$ 10.00$ & $\$ 12.00$ & \\
\hline
\end{tabular}

The optimal objective function value is $\$ 37,250$. The optimal flows are shown below:

\begin{tabular}{|c|c|c|c|c|c|}
\hline Source & Market 1 & Market 2 & Market 3 & Market 4 & Supply \\
\hline Source 1 & 1820 & 0 & 0 & 0 & 5000 \\
\hline Source 2 & 0 & 0 & 820 & 640 & 6000 \\
\hline Source 3 & 0 & 2220 & 0 & 280 & 2500 \\
\hline Demand & 1820 & 2220 & 820 & 920 & \\
\hline
\end{tabular}

Sensitivity information reported by the LP solver is as follows:

\begin{tabular}{|c|c|c|c|c|c|}
\hline Cell & $\begin{array}{c}\text { Final } \\
\text { Value }\end{array}$ & $\begin{array}{c}\text { Shadow } \\
\text { Price }\end{array}$ & $\begin{array}{c}\text { Constraint } \\
\text { R.H. Side }\end{array}$ & $\begin{array}{c}\text { Allowable } \\
\text { Decrease }\end{array}$ & $\begin{array}{c}\text { Allowable } \\
\text { Increase }\end{array}$ \\
\hline Source 1 Shipped & 1820 & 0 & 5000 & 3180 & $1 \mathrm{E}+30$ \\
\hline Source 2 Shipped & 1460 & 0 & 6000 & 4590 & $1 \mathrm{E}+30$ \\
\hline Source 3 Shipped & 2500 & 1 & 2500 & 280 & 640 \\
\hline Received Market 1 & 1820 & 7.5 & 1820 & 1820 & 3180 \\
\hline Received Market 2 & 2220 & 6 & 2220 & 640 & 280 \\
\hline Received Market 3 & 820 & 5 & 820 & 820 & 4540 \\
\hline Received Market 4 & 920 & 4 & 920 & 640 & 4540 \\
\hline
\end{tabular}



follows:

From this information, we can use eq. (16) compute the adjusted shadow prices and effective limits of validity as

\begin{tabular}{|c|c|c|c|c|}
\hline Market & $\begin{array}{c}\text { LP-Reported Shadow } \\
\text { Price }\end{array}$ & ASP & $\begin{array}{c}\text { Effective Lower Limit } \\
\text { of Demand }\end{array}$ & $\begin{array}{c}\text { Effective Upper Limit } \\
\text { of Demand }\end{array}$ \\
\hline Market 1 & 7.5 & 2.95 & 1620 & 2020 \\
\hline Market 2 & 6 & -5.10 & 2020 & 2420 \\
\hline Market 3 & 5 & -1.84 & 700 & 940 \\
\hline Market 4 & 4 & -14.42 & 870 & 970 \\
\hline
\end{tabular}

From the above calculations, we see how profit changes at each market with one unit change in delivered quantity. Since Market 4 has the biggest absolute value for $A S P$, we choose Market 4 for demand modification. For this market, note that the effective range of $A S P$ was computed as: $[\max \{920-640,1520-50 \times 13\}, \min \{920+4540,1520-$ $50 \times 11\}]=[870,970]$. Since $A S P_{4}$ is negative, $D_{4}$ should be decreased as much as possible. Therefore, we set $D_{4}$ to its effective lower limit of 870 and re-solve the transportation problem, and repeat the cycle. The iterations of the heuristic are:

Iteration 1: Objective Value $\$ 37,250$

\begin{tabular}{|c|c|c|c|c|c|}
\hline Market & Current Price & Current Demand & Shadow Price & ASP & Remark \\
\hline Market 1 & $\$ 10.50$ & 1820 & 7.5 & 2.95 & \\
\hline Market 2 & 9.00 & 2220 & 6 & -5.10 & \\
\hline Market 3 & 10.00 & 820 & 5 & -1.84 & \\
\hline Market 4 & 12.00 & 920 & 4 & -14.42 & $\begin{array}{c}\text { Set } D_{4}=870 \\
\left.\text { (at } P_{4}=\$ 13\right) \\
\text { for the next } \\
\text { iteration }\end{array}$ \\
\hline
\end{tabular}

Iteration 2: Objective Value \$37,920

\begin{tabular}{|c|c|c|c|c|c|}
\hline Market & Current Price & Current Demand & Shadow Price & ASP & Remark \\
\hline Market 1 & $\$ 10.50$ & 1820 & 7.5 & 2.95 & $\begin{array}{c}\text { Set } D_{2}=2020 \\
\left(P_{2}=\$ 10\right)\end{array}$ \\
\hline Market 2 & 9.00 & 2220 & 6 & -5.10 & -1.84 \\
\hline Market 3 & 10.00 & 820 & 5 & -12.42 & $\begin{array}{c}\text { Blocked } \\
\text { (already at the } \\
\text { lower limit) }\end{array}$ \\
\hline Market 4 & 13.00 & 870 & 5 & & \\
\end{tabular}

At Iteration 2, Market 4 had the highest absolute value for ASP. Since this value (-12.42) is negative, it indicates that we should decrease the demand at Market 4 to its effective lower limit. However, this demand quantity is already at its effective lower limit of 870 and, hence, is blocked. So we proceed with the next best ASP (Market 2 with -5.10). The effective lower limit at this market is 2020, so we set $D_{2}$ to 2020 (corresponds to a price of $\$ 10$ ).

Iteration 3: Objective Value \$38,740

\begin{tabular}{|c|c|c|c|c|c|}
\hline Market & Current Price & Current Demand & Shadow Price & ASP & Remark \\
\hline Market 1 & $\$ 10.50$ & 1820 & 7.5 & 2.95 & $\begin{array}{c}\text { Set } D_{l}=2020 \\
\left(P_{l}=\$ 10\right)\end{array}$ \\
\hline Market 2 & 10.00 & 2020 & 7 & -3.10 & Blocked \\
\hline Market 3 & 10.00 & 820 & 5 & -1.84 & Blocked \\
\hline Market 4 & 13.00 & 870 & 5 & -12.42 & . \\
\hline
\end{tabular}

At Iteration 3, both Markets 2 and 4 are blocked, so we are forced to choose the third best ASP (Market 1). We increase the demand at Market 1 (its ASP is positive) to its effective upper limit of 2020 (this corresponds to a price of $\$ 10$ ). 
Iteration 4: Objective Value $\$ 39,230$

\begin{tabular}{|c|c|c|c|c|c|}
\hline Market & Current Price & Current Demand & Shadow Price & $\boldsymbol{A S P}$ & Remark \\
\hline Market 1 & $\$ 10.00$ & 2020 & 7 & 1.95 & Blocked \\
\hline Market 2 & 10.00 & 2020 & 7 & -3.10 & Blocked \\
\hline Market 3 & 10.00 & 820 & 5 & -1.84 & $\begin{array}{c}\text { Set } D_{3}=700 \\
\left(P_{3}=\$ 11\right)\end{array}$ \\
\hline Market 4 & 13.00 & 870 & 5 & -12.42 & Blocked \\
\hline
\end{tabular}

At Iteration 4, the only available choice is Market 3 whose demand should be reduced to 700 (at a price of \$11).

Iteration 5: Objective Value \$39,330

\begin{tabular}{|c|c|c|c|c|c|}
\hline Market & Current Price & Current Demand & Shadow Price & ASP & Remark \\
\hline Market 1 & $\$ 10.00$ & 2020 & 7 & 1.95 & Blocked \\
\hline Market 2 & 10.00 & 2020 & 7 & -3.10 & Blocked \\
\hline Market 3 & 11.00 & 700 & 6 & 0.16 & $\begin{array}{c}\text { Set } D_{3}=940 \\
\left(P_{3}=\$ 9\right)\end{array}$ \\
\hline Market 4 & 13.00 & 870 & 5 & -12.42 & Blocked \\
\hline
\end{tabular}

At Iteration 5, we reset the demand of Market 3 this time to its upper limit of 940 (at a price of \$9).

\begin{tabular}{|c|c|c|c|c|c|}
\hline \multicolumn{6}{|c|}{ Iteration 6: Objective Value $\mathbf{\$ 3 8 , 8 9 0}$} \\
\hline Market & Current Price & Current Demand & Shadow Price & $A S P$ & Remark \\
\hline Market 1 & $\$ 10.00$ & 2020 & 7 & 1.95 & The method \\
\hline Market 2 & 10.00 & 2020 & 7 & -3.10 & terminates here \\
\hline Market 3 & 9.00 & 940 & 4 & -3.85 & because the \\
\hline Market 4 & 13.00 & 870 & 5 & -12.42 & $\begin{array}{l}\text { objective function } \\
\text { value is worse than } \\
\text { at the previous } \\
\text { iteration. }\end{array}$ \\
\hline
\end{tabular}

This is the first iteration at which the objective function value has failed to improve, so the method is terminated. The best solution found is the one at the previous iteration (Iteration 5) with a price vector of $(\$ 10, \$ 10, \$ 11, \$ 13)$ at the four markets. The corresponding demand quantities are: 2020, 2020, 700, and 870, respectively. The objective function value is $\$ 39,330$. The progress of the heuristic is depicted in Figure 3.

\section{GRID SEARCH}

To evaluate the effectiveness of the heuristic method, we solve model (P2) using an alternative method-a "brute-force" enumeration using a grid search. At each grid point (price vector), the corresponding standard transportation problem (P1) is solved using Excel Solver [see e.g. Ragsdale (2004)] and the optimal objective value is recorded. Using integer step-sizes for the price at each market, there are $2 \times 3 \times 3 \times 3=54$ price vectors. The maximum among these 54 optimal transportation problem objective function values determines the optimal solution to (P2). A final iteration then recreates the optimal transportation model solution corresponding to the best price vector found. To carry out the grid search efficiently, we used VBA (Visual Basic for Applications) to provide a programming loop that enabled the repeated invocation of Solver and to keep track of the objective values at the intermediate steps. Details of VBA programming may be found in Albright (2001). While we have assumed linearity of the demand function for convenience, the search strategy can be employed for any type of function including ones defined only empirically. The results of the grid search (Table 3) indicate that the optimal solution is at price vector 27. This is precisely the same solution as the one obtained by the heuristic in only 6 iterations. The savings in computational effort due to the heuristic is, therefore, [54 - 6] / 54, or 89\%, over a full search. 


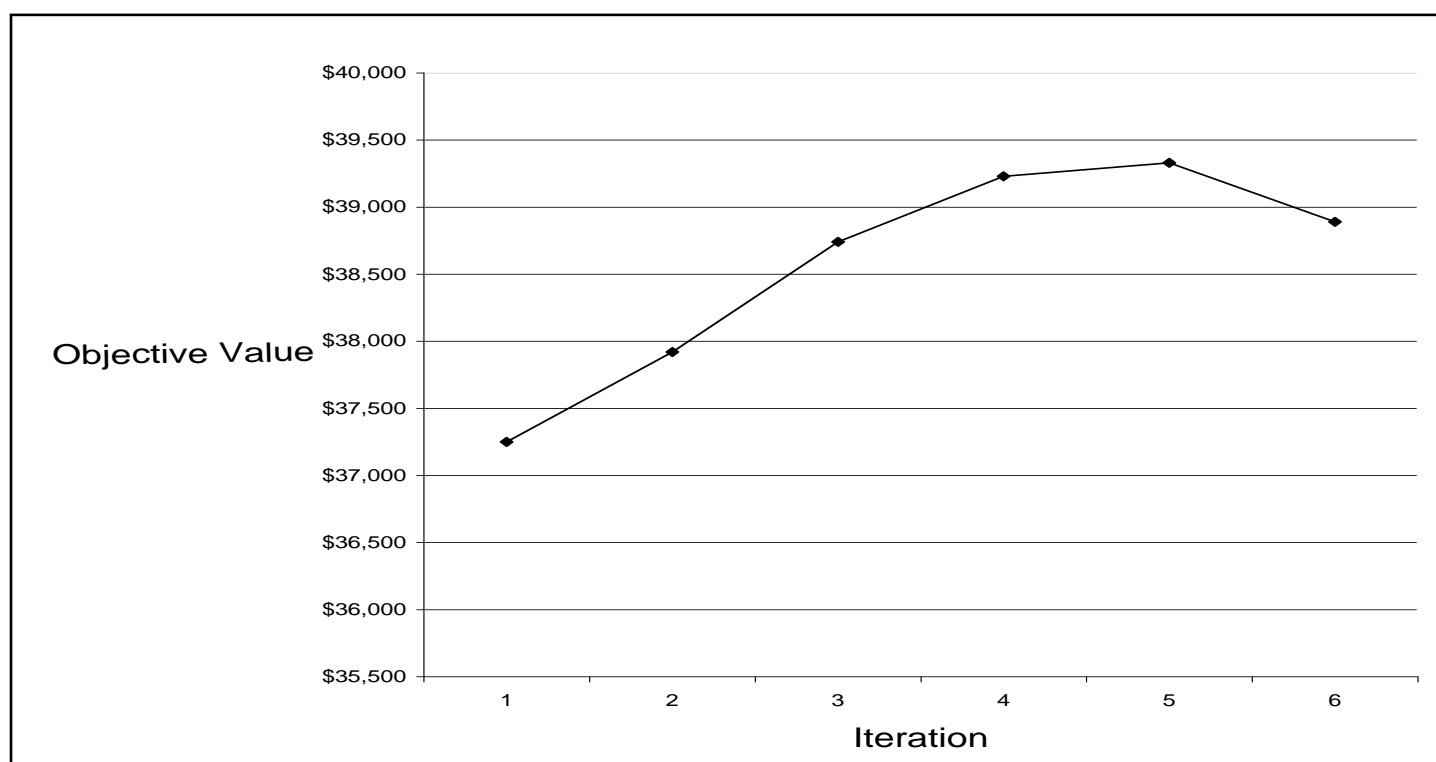

Figure 3. Trajectory of Heuristic

Table 3: Results Of Grid Search

\begin{tabular}{|c|c|c|c|c|c|}
\hline \multirow[b]{2}{*}{ Price Vector } & \multicolumn{4}{|c|}{ Price At } & \multirow{2}{*}{$\begin{array}{c}\text { Objective } \\
\text { Function } \\
\text { Value }\end{array}$} \\
\hline & Market 1 & Market 2 & Market 3 & Market 4 & \\
\hline 1 & $\$ 10$ & $\$ 8$ & $\$ 9$ & $\$ 11$ & $\$ 35,410$ \\
\hline 2 & 10 & 8 & 9 & 12 & 36,180 \\
\hline 3 & 10 & 8 & 9 & 13 & 36,850 \\
\hline 4 & 10 & 8 & 10 & 11 & 35,750 \\
\hline 5 & 10 & 8 & 10 & 12 & 36,520 \\
\hline 6 & 10 & 8 & 10 & 13 & 37,190 \\
\hline 7 & 10 & 8 & 11 & 11 & 35,850 \\
\hline 8 & 10 & 8 & 11 & 12 & 36,620 \\
\hline 9 & 10 & 8 & 11 & 13 & 37,290 \\
\hline 10 & 10 & 9 & 9 & 11 & 36,630 \\
\hline 11 & 10 & 9 & 9 & 12 & 37,400 \\
\hline 12 & 10 & 9 & 9 & 13 & 38,070 \\
\hline 13 & 10 & 9 & 10 & 11 & 36,970 \\
\hline 14 & 10 & 9 & 10 & 12 & 37,740 \\
\hline 15 & 10 & 9 & 10 & 13 & 38,410 \\
\hline 16 & 10 & 9 & 11 & 11 & 37,070 \\
\hline 17 & 10 & 9 & 11 & 12 & 37,840 \\
\hline 18 & 10 & 9 & 11 & 13 & 38,510 \\
\hline 19 & 10 & 10 & 9 & 11 & 37,450 \\
\hline 20 & 10 & 10 & 9 & 12 & 38,220 \\
\hline 21 & 10 & 10 & 9 & 13 & 38,890 \\
\hline 22 & 10 & 10 & 10 & 11 & 37,790 \\
\hline 23 & 10 & 10 & 10 & 12 & 38,560 \\
\hline 24 & 10 & 10 & 10 & 13 & 39,230 \\
\hline 25 & 10 & 10 & 11 & 11 & 37,890 \\
\hline 26 & 10 & 10 & 11 & 12 & 38,660 \\
\hline 27 & 10 & 10 & 11 & 13 & 39,330 \\
\hline 28 & 11 & 8 & 9 & 11 & 34,230 \\
\hline
\end{tabular}




\begin{tabular}{|c|c|c|c|c|c|}
\hline 29 & 11 & 8 & 9 & 12 & 35,000 \\
\hline 30 & 11 & 8 & 9 & 13 & 35,670 \\
\hline 31 & 11 & 8 & 10 & 11 & 34,570 \\
\hline 32 & 11 & 8 & 10 & 12 & 35,340 \\
\hline 33 & 11 & 8 & 10 & 13 & 36,010 \\
\hline 34 & 11 & 8 & 11 & 11 & 34,670 \\
\hline 35 & 11 & 8 & 11 & 12 & 35,440 \\
\hline 36 & 11 & 8 & 11 & 13 & 36,110 \\
\hline 37 & 11 & 9 & 9 & 11 & 35,450 \\
\hline 38 & 11 & 9 & 9 & 12 & 36,220 \\
\hline 39 & 11 & 9 & 9 & 13 & 36,890 \\
\hline 40 & 11 & 9 & 10 & 11 & 35,790 \\
\hline 41 & 11 & 9 & 10 & 12 & 36,560 \\
\hline 42 & 11 & 9 & 10 & 13 & 37,230 \\
\hline 43 & 11 & 9 & 11 & 11 & 35,890 \\
\hline 44 & 11 & 9 & 11 & 12 & 36,660 \\
\hline 45 & 11 & 9 & 11 & 13 & 37,330 \\
\hline 46 & 11 & 10 & 9 & 11 & 36,270 \\
\hline 47 & 11 & 10 & 9 & 12 & 37,040 \\
\hline 48 & 11 & 10 & 9 & 13 & 37,710 \\
\hline 49 & 11 & 10 & 10 & 11 & 36,610 \\
\hline 50 & 11 & 10 & 10 & 12 & 37,380 \\
\hline 51 & 11 & 10 & 10 & 13 & 38,050 \\
\hline 52 & 11 & 10 & 11 & 11 & 36,710 \\
\hline 53 & 11 & 10 & 11 & 12 & 37,480 \\
\hline 54 & 11 & 10 & 11 & 13 & 38,150 \\
\hline
\end{tabular}

\section{CONCLUSION}

In this paper, we have developed a heuristic approach to the problem of simultaneously determining prices and shipment quantities in a supply network consisting of multiple sources and markets. The heuristic is based on shadow price information that can be obtained from a linear programming solution of the underlying transportation model. By analyzing the shadow prices, a trajectory can be chosen for improving the objective function value. The method is illustrated on a numerical example that demonstrates the potential for huge savings in computational effort over a full search. This approach can easily be extended to any type of demand function: linear, nonlinear, discrete, or even empirical. It can also be extended to the supply side to incorporate production functions.

\section{REFERENCES}

1. Albright, S. C. (2001). VBA for Modelers: Developing Decision Support Systems with Microsoft@ Excel, Duxbury/Thomson Learning.

2. Chopra, S. and P. Meindl (2004). Supply Chain Management: Strategy, Planning, and Operation, Second Edition, Prentice-Hall.

3. Dökmeci, V. F. (1989). Multi-Plant Location With Respect to Uniform Pricing, The Annals of Regional Science 23(1), 29-39.

4. Duke, C. R. (1994). Matching Appropriate Pricing Strategy with Markets and Objectives, Journal of Product and Brand Management 3(2), 12-27.

5. Ragsdale, C. T. (2004). Spreadsheet Modeling and Decision Analysis: A Practical Introduction to Management Science, Fourth Edition, Thomson/South-Western. 